\title{
Magnetic signature of Siaolin Village, southern Taiwan, after burial by a catastrophic landslide due to Typhoon Morakot
}

\author{
W.-B. Doo ${ }^{1}$, S.-K. Hsu ${ }^{1}$, C.-C. Chen ${ }^{1}$, H.-H. Hsieh ${ }^{1}$, H.-Y. Yen ${ }^{1}$, Y.-G. Chen ${ }^{2}$, and W.-Y. Chang ${ }^{3}$ \\ ${ }^{1}$ Institute of Geophysics and Department of Earth Sciences, National Central University, Jhongli, Taoyuan 320, Taiwan \\ ${ }^{2}$ Department of Geosciences, National Taiwan University, Taipei 106, Taiwan \\ ${ }^{3}$ Department of Natural Sciences, National Science Council, Taipei 106, Taiwan
}

Received: 6 July 2010 - Revised: 22 November 2010 - Accepted: 4 January 2011 - Published: 10 March 2011

\begin{abstract}
Typhoon Morakot caused terrible flooding and torrential rains that severely damaged southern Taiwan. Swollen rivers wiped out roads and demolished buildings. Long-lasting and intense rainfall triggered landslides in many regions in southern Taiwan, including the landslide that buried Siaolin Village in Kaohsiung County and killed approximately 500 people. Locating buried buildings immediately after a landslide could be an emergent issue in life saving and hazard mitigation. Analyzing the magnetic signature of a buried area is an efficient and non-destructive way to detect subsurface buildings. This paper presents the results of a magnetic survey for the purpose of outlining subsurface images of Siaolin Village after the catastrophic landslide induced by Typhoon Morakot in 2009. We found that a high-resolution magnetic survey can reveal suspected building positions that match the initial locations of buildings in Siaolin Village. The estimated depths of the buried buildings are $5-10 \mathrm{~m}$ deep. The magnetic data further suggest a possible debris-flow direction of NE to SW because the northern part of the village was mostly destroyed, while buildings in the southern part of the village remained in place.
\end{abstract}

\section{Introduction}

Typhoons frequently strike Taiwan between summer and fall. According to statistics from the Central Weather Bureau of Taiwan, approximately four typhoons per year have hit Taiwan since 2000. Typhoons consist of high-speed winds and rain. Quickly accumulating rainwater often causes floods and, in many cases, landslides. On 7 August 2009, Typhoon

Correspondence to: C.-C.Chen (chencc@earth.ncu.edu.tw)
Morakot brought heavy rainfall to the southern part of Taiwan. According to the Central Weather Bureau of Taiwan, Typhoon Morakot dumped more than $2500 \mathrm{~mm}$ of rain over three days starting on 7 August 2009. This amount of rain is comparable to the average annual precipitation in Taiwan, and, thus, this rainfall caused floods and landslides. These landslides destroyed and buried many villages in Kaohsiung County; among these villages, Siaolin Village suffered the worst damage.

Based on field investigations, the landslide in the Siaolin region affected an area $1000 \mathrm{~m}$ wide and $3500 \mathrm{~m}$ long (Fig. 1), and the landslide completely buried Siaolin Village. Changes in elevation before and after Typhoon Morakot (Fig. 1b) were derived from digital terrain models (DTMs) with a precision of five meters by the Agriculture and Forestry Aerial Survey Institute of Taiwan. According to the DTMs before and after Typhoon Morakot, the volume of the major landslide body (cool colors in Fig. 1b) was about 23.87 million $\mathrm{m}^{3}$, with an average depth of $42 \mathrm{~m}$ and an extent of 57 ha. The sliding block was mainly composed of Pliocene shale and Quaternary colluvium. The sliding surface may have been located along an interface between fresh and weathered Pliocene shale. The National Disasters Prevention and Protection Commission of Taiwan reported 724 deaths that were caused by the flooding during Typhoon Morakot. The landslide at Siaolin Village was responsible for 474 of these deaths.

Siaolin Village is located in Kaohsiung County in southern Taiwan. The Nantzuhsien River (also called the Cishan River) borders the west side of the village (Fig. 2a). At its shallowest point, the river measures about $345 \mathrm{~m}$ in elevation. Sian-Du Mountain, at an altitude of $1445 \mathrm{~m}$, borders the east side of the village (Fig. 1a). The elevation difference between the east and west sides is more than $1000 \mathrm{~m}$, with a

Published by Copernicus Publications on behalf of the European Geosciences Union. 

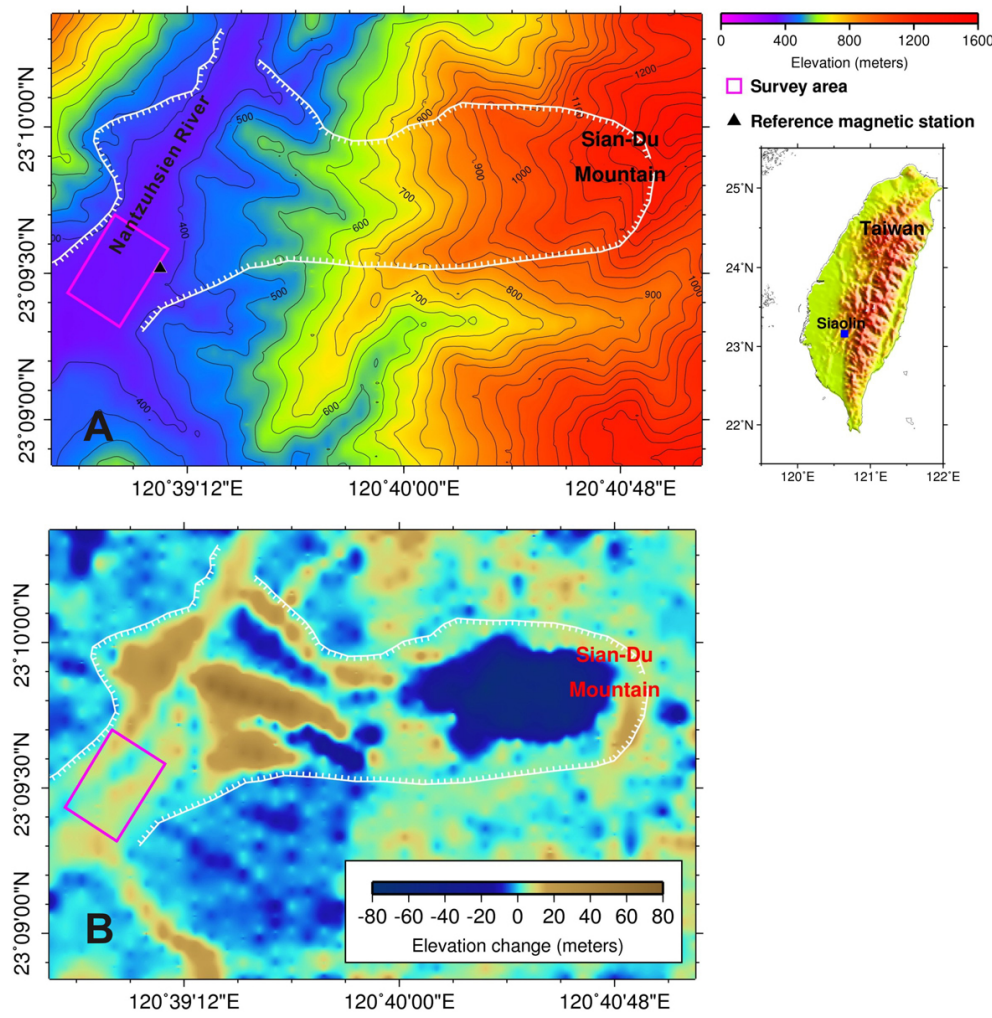

Fig. 1. (a) The topography and (b) its changes due to the landslide event in the Siaolin area. Purple rectangles in each plot indicate the areas of the magnetic survey.

slope of approximately 20 degrees. Initially, $\sim 150$ buildings made up Siaolin Village (Fig. 2a). However, after Typhoon Morakot, only one or two remained (Fig. 2b).

To identify the locations of the buried buildings, a magnetic survey (Fig. 2) was conducted immediately after the catastrophic landslide. Magnetic anomalies come from different magnetic susceptibilities or the magnetization contrast of different materials (Table 1; Nabighian, 1972; Hsu et al., 1996; Doo et al., 2009). A high-resolution magnetic anomaly map is essential to quickly understand the characteristics of subsurface materials. In general, the magnetization of buildings is much larger than that of mud or other geological sediments because the buildings are constructed using steel ties (Table 1). Magnetic data can thus be expected to identify the outlines of the buried buildings in Siaolin Village. This study presents the results of a quick magnetic investigation of Siaolin Village and the implications to the kinematics associated with the Siaolin landslide.

\section{Data and methods}

After the typhoon, we collected magnetic data at the village location and surveyed most of the relatively flat area above the township of Siaolin Village (rectangles in Figs. 1 and 2). The track lines of magnetic measurement were along the direction of NW to SE (with an interval of $5 \mathrm{~m}$ ). The data
Table 1. Density and susceptibility of rocks and iron oxides.

\begin{tabular}{llc}
\hline Material & $\begin{array}{l}\text { Density }(\rho) \\
\left(\mathrm{g} \mathrm{cm}^{-3}\right)\end{array}$ & $\begin{array}{c}\text { Susceptibility }(\kappa) \\
(\mathrm{SI})\end{array}$ \\
\hline Shale & 2.10 & $0-0.019$ \\
Sandstone & 2.24 & $0-0.021$ \\
$\mathrm{FeO}$ & 5.745 & $5.20 \times 10^{5}$ \\
$\mathrm{Fe}_{2} \mathrm{O}_{3}$ & 5.24 & $2.36 \times 10^{5}$ \\
\hline
\end{tabular}

were collected in October 2009. We held a portable magnetometer at 1.22 or $1.82 \mathrm{~m}$ above the ground and recorded the total-field magnetic data. Portable proton precession magnetometers (Geometrics model G-856, with a sensitivity of $0.1 \mathrm{nT}$ ) were used in the magnetic surveys. To ensure measurement reliability, the magnetic data were measured at least three times at each location within a few minutes. If the standard deviation of readings was less than $10 \mathrm{nT}$, we calculated the average to represent the value of the total magnetic field at each location. We also set up a reference magnetic station (Fig. 1a) to continuously record the magnetic fluctuations with a sampling interval of $15 \mathrm{~s}$. Using this continuous data, we performed a diurnal variation correction on the observations. 

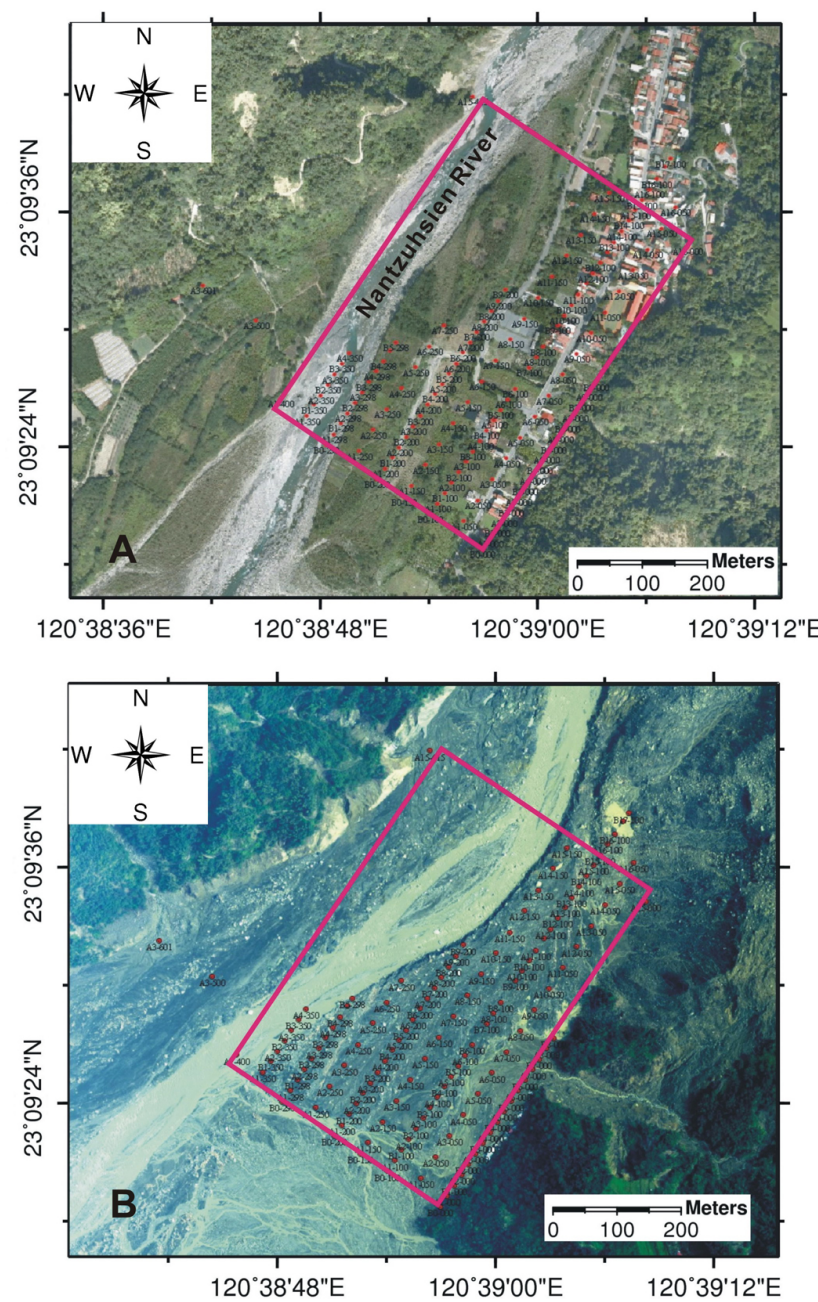

Fig. 2. Aerial photographs of Siaolin Village taken (a) before and (b) after Typhoon Morakot. Red dots are leveling benchmarks for positioning. Purple rectangles in each photo indicate the areas of the magnetic survey. Note that the main course of the Nantzuhsien River was slightly diverted to the east after Typhoon Morakot.

All of the raw readings are given in the histograms of Fig. 3 for the two measured heights of 1.22 and $1.82 \mathrm{~m}$. It should be noted that two groups of data points, at both the high and low ends, can be observed in these two histograms of raw data. The magnetic anomalies (Fig. $4 a$ and $b$ ) were then obtained by subtracting the mean value of the survey data.

The analytic signal technique is widely used to detect subsurface magnetic source boundaries (e.g., Nabighian, 1972, 1974, 1984; Roest et al., 1992; Hsu et al., 1996, 1998; Hsu, 2002; Fedi and Florio, 2001; Salem and Ravat, 2003; Doo et al., 2007, 2009). The enhanced analytic signal is composed of the nth-order vertical derivative values of two horizontal gradients and one vertical gradient. In general, the vertical gradient can be derived from the Hilbert transform of the horizontal gradients. In this study, we additionally measured
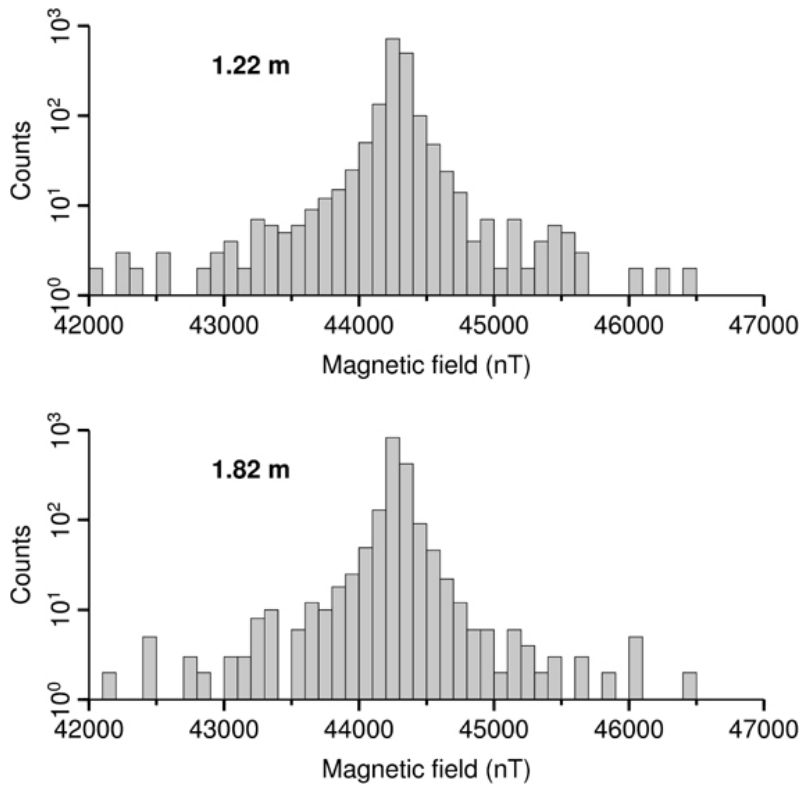

Fig. 3. Histograms of raw magnetic readings measured at heights of 1.22 (upper panel) and 1.82 (lower panel) $\mathrm{m}$ above the ground. Note that there are two groups of data points, at the high and low ends, in both histograms.

magnetic data at different heights for each location. Thus, we were able to directly estimate the vertical gradient from the survey data (Fig. 4c). This direct estimation made the results more reliable.

We determined the boundaries and the buried depths of the buildings following the method proposed by Hsu et al. (1996). As suggested by Hsu et al. (1996), the geological boundaries were estimated by tracing the maximum amplitudes of the analytic signal. Likewise, by applying this method, we were able to determine the morphological boundaries of the buildings buried by the landslide. The depth of each geological/morphological boundary can also be estimated from the amplitude ratio of the enhanced and simple analytic signals using the following equation: $d=$ $\sqrt{2} \cdot \sqrt{\frac{A_{0}(x, y)}{A_{2}(x, y)}}$ (Hsu et al., 1996). In this equation, $d$ indicates the depth to the boundary, and $A_{0}$ and $A_{2}$ indicate the amplitudes of the simple analytic signal and the enhanced second-order analytic signal, respectively. For details, we refer readers to the paper of Hsu et al. (1996) and a recent paper by Doo et al. (2007).

\section{Results and resolution test}

We obtained two maps of magnetic anomalies, one at 1.22 (Fig. 4a) and the other at 1.82 (Fig. 4b) m above the ground. According to the magnetic anomaly maps, high-amplitude magnetic anomalies were present in the 

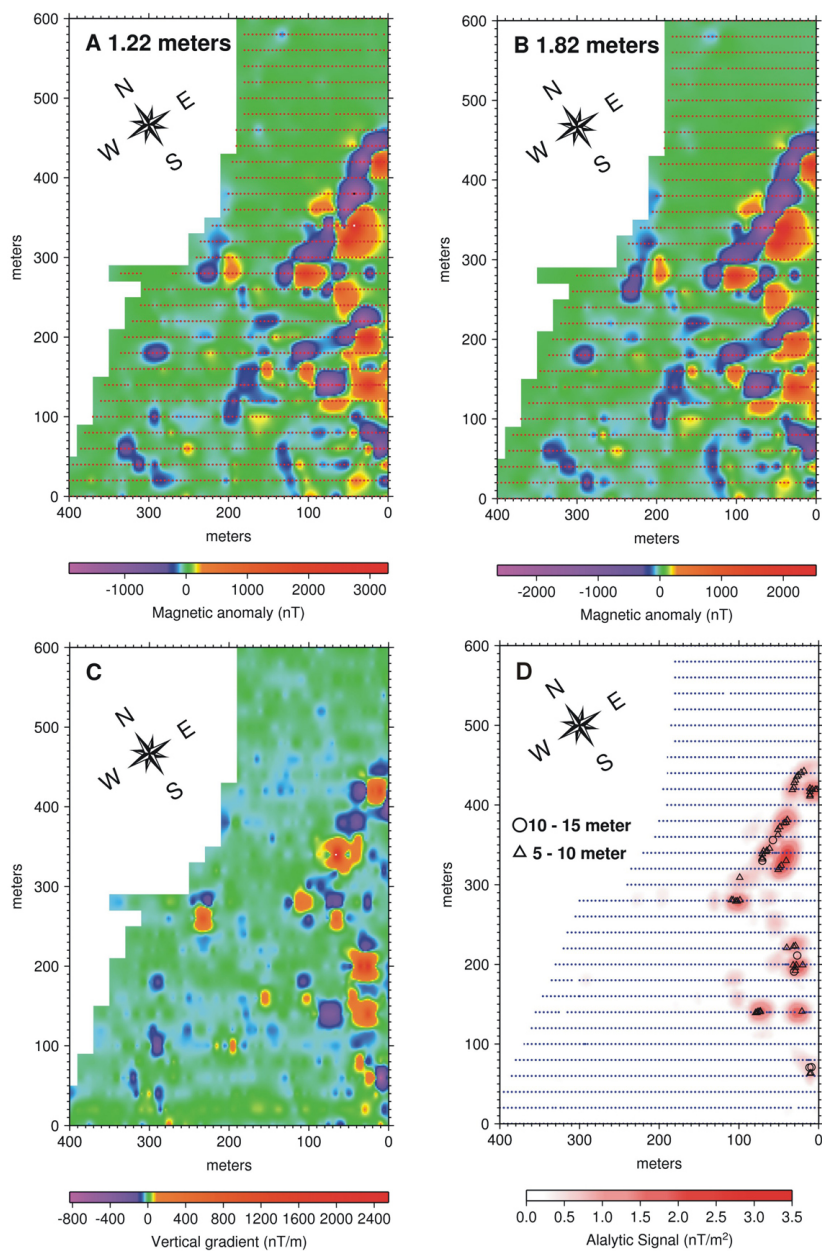

Fig. 4. Magnetic anomaly maps at (a) $1.22 \mathrm{~m}$ and (b) $1.82 \mathrm{~m}$ above the ground; (c) vertical gradients of magnetic fields obtained from the differences in magnetic data between (a) and (b); and (d) the first-order analytic signal together with source depth solutions (triangles and circles). Both red and blue dots indicate surveying points for magnetic data.

southeastern quadrant of our survey area. These anomalies may be associated with the buried buildings of Siaolin Village. It should be noted that before Typhoon Morakot the buildings in the village were originally located both in the northeastern and southeastern quadrants of the survey area (Fig. 2a). These anomalies thus suggest a pattern of redistribution of the damaged and buried buildings. The overall magnetic anomaly patterns in Fig. $4 \mathrm{a}$ and $\mathrm{b}$ are quite similar, thereby suggesting data reliability. Moreover, the vertical gradient distribution (Fig. 4c) also showed a pattern similar to that of the magnetic anomalies.

Figure $4 \mathrm{~d}$ shows the results of the distribution of the firstorder enhanced analytic signal. In the study area, the sources of magnetic anomalies primarily come from contrasts between the buildings and covering sediments brought by the

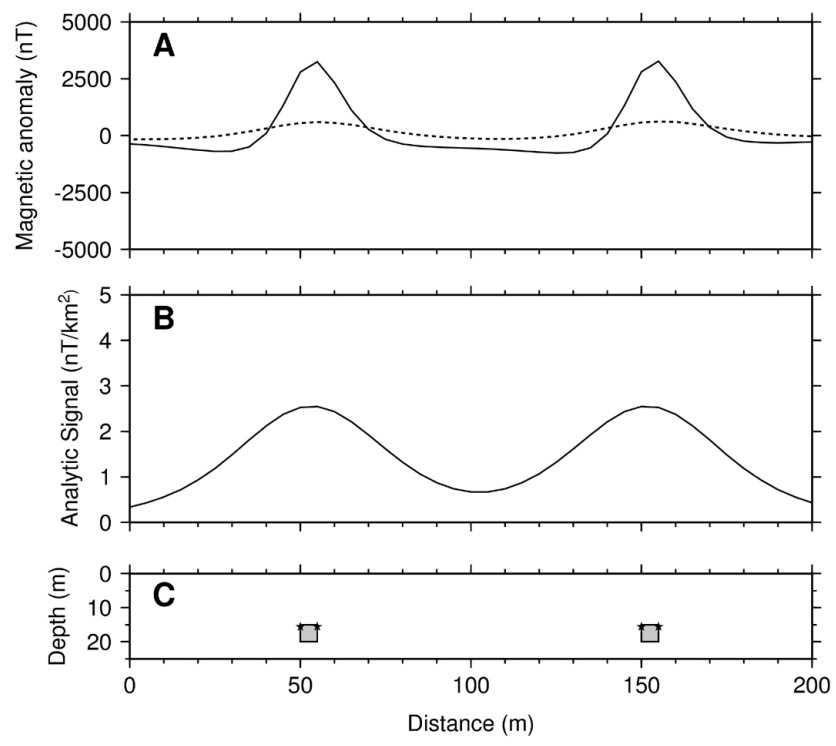

Fig. 5. (a) The solid line indicates the magnetic anomaly calculated from the two prisms shown in (c), and the dashed line indicates the upward continuation of the anomaly at $20 \mathrm{~m}$; (b) analytic signal of (a); and (c) test model consisting of two prisms with dimensions of $5 \mathrm{~m} \times 5 \mathrm{~m}$. Black stars indicate the calculated depths for the prisms.

landslide event. Thus, large amplitudes of the magnetic analytic signal indicate the possible locations of buildings. Because the high amplitude values of the analytic signals were primarily distributed in the southeastern region, the remaining buildings may still exist there underground. Figure $4 \mathrm{~d}$ also shows the results of the estimated depths of the boundaries. The depths of the suspected buildings were typically five to ten meters deep, as indicated by the triangles in Fig. 4d.

To demonstrate the feasibility of the proposed method, we determined whether our layout of magnetic data could resolve the small targets representing buried buildings. We constructed a model (Fig. 5c) consisting of two square prisms of $5 \mathrm{~m} \times 5 \mathrm{~m}$ to represent the buried buildings. The distance between the ground and the top surface of each prism was $15 \mathrm{~m}$. Considering the artificial buildings as aggregates of concrete and steel, the susceptibility of each prism was about $10 \%$ of $\mathrm{FeO}$ (Table 1). The magnetic sampling points were evenly spaced at intervals of $5 \mathrm{~m}$, the same as in our survey layout. Figure 5a shows the magnetic anomaly (solid line), together with its upward continuation at $20 \mathrm{~m}$ (dashed line). We then calculated the analytic signal (Fig. 5b). It should be noted that the orders of magnitude for both the magnetic anomaly and the analytic signal were very close to those of the observations. The buried depths of the prisms were estimated to be $15.6 \mathrm{~m}$ (black stars in Fig. 5c). This modeling experiment confirmed that the resolution of the observed magnetic data is sufficient to detect buried buildings. 


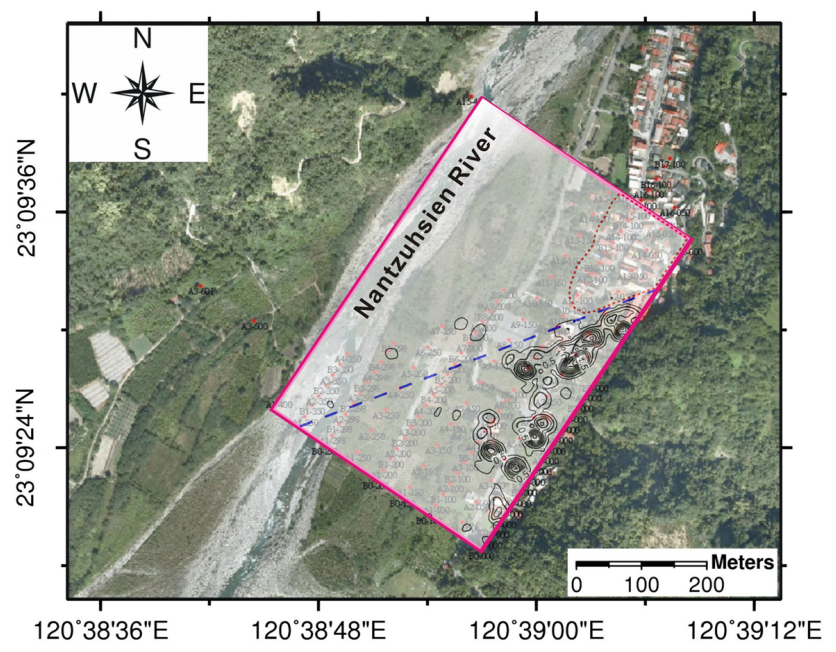

Fig. 6. Superposing the distributions of the first-order analytic signals (contours) onto an aerial photograph taken before Typhoon Morakot. The thick dashed line indicates the destruction frontier of the landslide suggested by the magnetic survey. Buildings in the area encircled by the red dotted curve were destroyed and removed by the landslide impact.

\section{Discussion and concluding remarks}

The above magnetic results have important implications for the Siaolin landslide. After superposing the distribution of analytic signals (contours in Fig. 6) onto the aerial photograph taken before Typhoon Morakot, we found that most of the building locations in the southeastern quadrant of the survey area corresponded to high-amplitude analytic signals. In contrast, in the northeastern portion (the area indicated by the red dotted curve in Fig. 6), the magnetic anomaly signature was not significantly related to the original locations of buildings. It should be noted that because the magnetic survey was conducted over a relatively flat topography with a covering layer of about $10 \mathrm{~m}$ (as shown in Fig. 1b) and the buildings in the north were not buried much deeper than those in the south, it was not the buried depth that masked the buildings in the north. A comparison of the analytic signal results and the aerial photograph thus indicates a clear boundary (thick dashed line in Fig. 6) for the magnetic pattern and suggests that the landslide very likely dislocated buildings located to the north of that boundary. To the south of that boundary, the buildings remain in place and are buried.

The analytic signal results suggest a destruction frontier along the direction of $\sim \mathrm{N} 70^{\circ} \mathrm{E}$, as depicted by the thick dashed line in Fig. 6. North of the destruction frontier, landslide/debris-flow damaged and removed most of the buildings, while south of the destruction frontier, many of the buildings may have been spared from the impact of the landslide/debris-flow. Therefore, the transition from the de- structed to non-destructed zones due to landslide/debris-flow can be presented on a scale of several meters (Hsu, 2004). Furthermore, such a destruction frontier indicates a major flow direction along the NE to the SW for the sliding of materials into Siaolin Village. Such an inference based on the magnetic survey is supported by a very recent simulation of the Siaolin landslide by Kuo et al. (2010). The magnetic observations in this study thus provide a relevant constraint for further numerical simulation (e.g., Crosta et al., 2004; Kuo et al., 2009) of the flow pattern of the Siaolin landslide event (Kuo et al., 2010). Understanding and modeling the flow pattern is of considerable importance to identify potential hazardous sites to protect buildings, structures and people from avalanches, debris flows and rockfalls in the future.

The magnetic data also indicate another important validation of the burying process of Siaolin Village. Contrary to the destruction scenario involving a landslide occurring in the northeastern portion, the estimated depths of the buried buildings are 5-10 m (Fig. 4d) in the southeastern part of the survey area. As mentioned above, most of those buildings obviously stayed at their original locations without displacement (Fig. 6), and some may have even remained intact. Mud floods associated with the breached landslide dam and witnessed by the surviving villagers struck the southern part of the village about 30 min after the landslide and then completely covered the remnant village. A burying scenario happening in the southern part of the village validated by the magnetic survey is essentially different from the scenario in the northern part and is fundamental to the redistribution of the initial landslide material for the geomorphologic evolution in such an extreme event. The redistribution of the initial landslide material deposited by mud floods may also cause fatal destruction, as occurred in the Siaolin landslide.

Finally, in terms of hazard mitigation, near-surface high-resolution magnetic surveys, as demonstrated in this study, can be very helpful to identify subsurface buildings/structures buried around $10 \mathrm{~m}$. Surveying efficiency and resolution are practical problems in these surveys and should be improved for the purposes of saving lives and retrieving bodies.

Acknowledgements. This project was funded under grant NSC982745-M-008-013 of the National Science Council of Taiwan. Deepest appreciation is given to SeeHope Tech. \& Eng. Ltd. Co., Taiwan, for helping to collect the valuable magnetic data on Siaolin Village. The comments and suggestions from Fausto Guzzetti, Mark Pilkington and two anonymous reviewers are highly appreciated.

Edited by: F. Guzzetti

Reviewed by: M. Pilkington and two other anonymous referees 


\section{References}

Crosta, G. B., Chen, H., and Lee, C. F.: Replay of the 1987 Val Pola Landslide. Italian Alps, Geomorphology, 60, 127-146, 2004.

Doo, W. B., Hsu, S. K., and Yeh, Y. C.: A derivative-based interpretation approach to estimating source parameters of simple 2D magnetic sources from Euler deconvolution, the analytic-signal method and analytical expressions of the anomalies, Geophys. Prospect., 55, 255-264, 2007.

Doo, W. B., Hsu, S. K., Tsai, C. H., and Huang, Y. S.: Using analytic signal to determine magnetization/density ratios of geological structures, Geophys. J. Int., 179, 112-124, 2009.

Fedi, M. and Florio, G.: Detection of potential fields source boundaries by enhanced horizontal derivation method, Geophys. Prospect., 49, 40-58, 2001.

Hsu, K. J.: Physics of Sedimentology: Textbook and Reference, Springer-Verlag, Berlin, 2004.

Hsu, S. K.: Imaging magnetic sources using Euler's equation, Geophys. Prospect., 50, 15-25, 2002.

Hsu, S. K., Sibuet, J. C., and Shyu, C. T.: High-resolution detection of geologic boundaries from potential-field anomalies: an enhanced analytic signal technique, Geophysics 61, 373-386, 1996.

Hsu, S. K., Coppens, D., and Shyu, C. T.: Depth to magnetic source using the generalized analytic signal, Geophysics, 63, 19471957, 1998.
Kuo, C. Y., Tai, Y. C., Bouchut, F., Mangeney, A., Pelanti, M., Chen, R. F., and Chang, K. J.: Smulation of Tsaoling landslide, Taiwan, based on Saint Venant equations over general topography, Eng. Geol., 104, 181-189, 2009.

Kuo, C. Y., Tai, Y. C., Chen, C. C., Chang, K. J., Siau, A. Y., Dong, J. J., Han, R., Shimamoto, T., and Lee, C. T.: The landslide stage of the Siaolin catastrophe: simulation and validation, J. Geophys. Res.-Earth, revised, 2010.

Nabighian, M. N.: The analytic signal of two-dimensional magnetic bodies with polygonal cross-section: its properties and use for automated anomaly interpretation, Geophysics, 37, 507-517, 1972.

Nabighian, M. N.: Additional comments on the analytic signal of two-dimensional magnetic bodies with polygonal cross-section, Geophysics, 39, 85-92, 1974.

Nabighian, M. N.: Toward a three-dimensional automatic interpretation of potential field data via generalized Hilbert transforms: fundamental relations, Geophysics, 49, 957-966, 1984.

Roest, W. R., Verhoef, J., and Pilkington, M.: Magnetic interpretation using the 3-D analytic signal, Geophysics, 57, 116-125, 1992.

Salem, A. and Ravat, D.: A combined analytic signal and Euler method (AN-EUL) for automatic interpretation of magnetic data, Geophysics, 68, 1952-1961, 2003. 